\title{
INDIVIDUAL NEUTRON MONITORING IN WORKPLACES WITH MIXED NEUTRON/PHOTON RADIATION
}

T. Bolognese-Milsztajn ${ }^{1, *}$, D. Bartlett ${ }^{2}$, M. Boschung ${ }^{3}$, M. Coeck ${ }^{4}$, G. Curzio ${ }^{5}$, F. d'Errico ${ }^{5}$, A. Fiechtner ${ }^{3}$, V. Giusti ${ }^{5}$, V. Gressier ${ }^{1}$, J. Kyllönen ${ }^{6}$, V. Lacoste ${ }^{1}$, L. Lindborg 6 , M. Luszik-Bhadra ${ }^{7}$, C. Molinos ${ }^{2}$, G. Pelcot ${ }^{1}$, M. Reginatto ${ }^{7}$, H. Schuhmacher ${ }^{7}$, R. Tanner ${ }^{2}$, F. Vanhavere ${ }^{4}$ and D. Derdau ${ }^{8}$

${ }^{1}$ Institut de Radioprotection et de Sûreté Nucléaire, F-92265 Fontenay-aux-Roses, France

${ }^{2}$ National Radiological Protection Board, Chilton, Didcot OX11 0RQ, UK

${ }^{3}$ Paul Scherrer Institut, CH-5232 Villigen, Switzerland

${ }^{4}$ Studiecentrum voor Kernenergie - Centre d'étude de l'énergie nucléaire, B-2400 Mol, Belgium

${ }^{5}$ Dipartimento di Ingegneria Meccanica, Nucleare e della Produzione, I-56126 Pisa, Italy

${ }^{6}$ Statens strålskyddsinstitut, SE-171-16 Stockholm, Sweden

${ }^{7}$ Physikalisch-Technische Bundesanstalt, D-38116 Braunschweig, Germany

${ }^{8}$ Kernkraftwerk Krümmel GmbH, D-21502 Geesthacht, Germany

EVIDOS ('evaluation of individual dosimetry in mixed neutron and photon radiation fields') is an European Commission (EC)-sponsored project that aims at a significant improvement of radiation protection dosimetry in mixed neutron/photon fields via spectrometric and dosimetric investigations in representative workplaces of the nuclear industry. In particular, new spectrometry methods are developed that provide the energy and direction distribution of the neutron fluence from which the reference dosimetric quantities are derived and compared to the readings of dosemeters. The final results of the project will be a comprehensive set of spectrometric and dosimetric data for the workplaces and an analysis of the performance of dosemeters, including novel electronic dosemeters. This paper gives an overview of the project and focuses on the results from measurements performed in calibration fields with broad energy distributions (simulated workplace fields) and on the first results from workplaces in the nuclear industry, inside a boiling water reactor and around a spent fuel transport cask.

\section{INTRODUCTION}

EVIDOS is an European Commission (EC)-sponsored project which, over the course of almost $4 \mathrm{y}$, will perform an 'evaluation of individual dosimetry in mixed neutron and photon radiation fields'. One of the primary aims of the project is to establish whether innovative electronic dosemeters with direct reading allow improved determination of personal dose equivalent. This objective requires preliminary investigations in calibration fields followed by extensive in-field measurements in representative workplaces of the nuclear industry. Seven European research laboratories with recognised expertise in radiation protection and in detector development are involved in the project.

Reference methods for the determination of personal dose equivalent in workplace fields are a central part of this project. Because no current dosemeter gives correct results in all neutron fields, reference values have to be derived from spectrometry (with respect to the energy and direction of the radiation) and fluence-to-dose equivalent conversion coefficients.

Various measurement campaigns have already been performed, comprising 2 simulated workplace fields and 10 workplace fields in the nuclear industry.

*Corresponding author: teresa.bolognese@irsn.fr
While these complex measurements require a detailed analysis, which is still in progress, a selection of the results is already available and is presented here.

\section{MEASUREMENT CAMPAIGNS AND INSTRUMENTS USED}

In the early phases of the project, a series of representative workplaces in the nuclear industry in which workers can receive significant neutron doses were selected. For each workplace, some measurement points were selected in collaboration with the radiological safety officers of the inspected facilities. These workplaces permit a thorough test of the dosemeters since they differ widely in terms of dose rates, neutron/photon relative intensity, energy/ direction distributions and also temperature, pressure, humidity, acoustic noise, vibration, electromagnetic fields, etc.

The area monitors and the personal dosemeters employed in the project are listed in Table $1^{(1-17)}$. These instruments comprise commercial devices as well as laboratory prototypes developed by some of the partners. Only prototype dosemeters have reached the stage of well-characterised, lightweight battery-operated instrumentation with direct reading ${ }^{(18)}$ are utilised in the project. 
Table 1. Short description of the devices used in the EVIDOS project.

\begin{tabular}{|c|c|c|}
\hline $\begin{array}{l}\text { Name of } \\
\text { device }\end{array}$ & Short description & $\begin{array}{l}\text { Commercial }(\mathrm{c}) \text { or } \\
\text { prototype }(\mathrm{p})\end{array}$ \\
\hline Sievert instrument & $\begin{array}{l}\text { Low pressure proportional counters (one of tissue-equivalent } \\
\text { plastic and one of graphite) evaluated according to } \\
\text { the variance/covariance technique }\end{array}$ & $\mathrm{p}$ \\
\hline Berthold LB 6411 & Moderator type area monitor & $\mathrm{c}$ \\
\hline Harwell N91 & Moderator type area monitor & $\mathrm{c}$ \\
\hline Wendi-2 & Moderator type area monitor with tungsten loaded moderator ${ }^{(2)}$ & $\mathrm{c}$ \\
\hline Studsvik 2200's & Moderator type area monitor & $\mathrm{c}$ \\
\hline BAE SYSTEMS & Novel area monitor for $H^{*}(10)$ and $H_{\mathrm{p}}(10, \alpha)$ measurements ${ }^{(3)}$ & $\mathrm{p}$ \\
\hline Aloka PDM-313 & Electronic neutron dosemeter with one silicon detector ${ }^{(4)}$ & $\mathrm{c}$ \\
\hline Siemens EPD N & $\begin{array}{l}\text { Electronic photon/thermal neutron dosemeter with three } \\
\text { silicon detectors }{ }^{(4)}\end{array}$ & $\mathrm{c}$ \\
\hline Siemens EPD N2 & Electronic photon/neutrondosemeter with three silicon detectors ${ }^{(4)}$ & $\mathrm{c}$ \\
\hline PADC(CR-39) & Track-etch detector(chemical + electrochemical etching) ${ }^{(5)}$ & $\mathrm{c}$ \\
\hline Saphydose-n & Electronic neutron dosemeter using a segmentedsilicon diode ${ }^{(6)}$ & $\mathrm{c}$ \\
\hline DISN $1.25 \%(2 \mathrm{~mm})$ & $\begin{array}{l}\text { Differential reading of two ionisation chambers that are based on } \\
\text { Direct Ion Storage }{ }^{(7)}\end{array}$ & $\mathrm{p}$ \\
\hline DISN 4\% (1 mm) & $\begin{array}{l}\text { Differential reading of two ionisation chambers that arebased on } \\
\text { Direct Ion Storage }{ }^{(7)}\end{array}$ & $\mathrm{p}$ \\
\hline DOS-2002 & Electronic photon/neutron dosemeter with one silicon detector ${ }^{(8)}$ & $\mathrm{p}$ \\
\hline HpSLAB & Superheated drop detector inside a slab phantom ${ }^{(9)}$ & $\mathrm{p}$ \\
\hline BTI-PND & Fast neutron bubble detector ${ }^{(17)}$ & $\mathrm{c}$ \\
\hline $\mathrm{PND}+\mathrm{BDT}$ & $\begin{array}{l}\text { Combination of fast and thermal neutron } \\
\text { bubble detector }\end{array}$ & $\mathrm{c}$ \\
\hline
\end{tabular}

For a complete analysis of the results, the estimates provided by the individual devices are compared with the reference values for dose equivalent quantities determined using neutron and, eventually, photon spectrometry. In the case of neutrons, direction-differential fluence distributions are determined along with the energy-differential values. These are needed to correlate isotropic quantities, such as ambient dose equivalent, to non-isotropic ones, such as personal dose equivalent and effective dose. Reference field spectrometry providing energy-differential, direction-integrated fluence distributions are primarily performed with a Bonner-sphere system $^{(10)}$ for the entire energy range. The measurements of the double-differential (energy and direction) neutron fluence are performed with novel instruments based, respectively, on SDDspectrometers $^{(11)}$ and Si-diodes ${ }^{(12)}$, and employing dedicated numerical procedures (unfolding methods) for data analysis ${ }^{(16)}$. Information on the direction distribution of the fields is also derived from PADC track-etch detectors mounted on different sides of the slab phantom and from analysis of the different detector readings for a novel design of neutron survey instrument (BAE SYSTEMS) ${ }^{(3)}$.

In October 2002, prior to the campaigns in the workplaces, an intercomparison exercise was performed at the IRSN simulated workplace facility CANEL/T400 ${ }^{(13,14)}$ and at the thermal neutron source SIGMA ${ }^{(15)}$. The purpose of the exercise was to test some novel instruments and to verify the behaviour of all instruments in a well-established reference field similar to some of those encountered at workplaces. Following the intercomparison, two measurement campaigns have been performed:

(1) Campaign number 1 (April 2003) was carried out in Krümmel, Germany, inside a boiling water reactor building and around a storage cask containing spent fuel elements.

(2) Campaign number 2 (June 2003) was carried out in Mol, Belgium, at the Belgonucléaire MOX fuel element manufacturing plant and at the $\mathrm{SCK} \bullet \mathrm{CEN}$ VENUS research reactor.

One or two additional campaigns are scheduled for the year 2004: at the BNFL plutonium re-processing plant and thermal oxide re-processing plant in Sellafield (UK), and/or inside a pressurised water reactor building and around a transport cask in Ringhals, Sweden.

\section{PRELIMINARY RESULTS FROM MEASUREMENTS IN SIMULATED WORKPLACE FIELDS}

The responses of area monitors and personal dosemeters in the SIGMA thermal field and at the CANEL simulated workplace field are reported in Tables 2 and 3 , respectively. The personal dosemeters were irradiated on an ISO PMMA 
INDIVIDUAL MONITORING FOR MIXED NEUTRONIPHOTON RADIATION

Table 2. Ambient dose equivalent response of area monitors, $R_{H^{*}}=H^{*}(10)_{\text {measured }} I H^{*}(10)_{\text {reference }}$ and relative standard uncertainties.

\begin{tabular}{lcccc}
\hline & \multicolumn{3}{c}{ Facility } \\
\cline { 2 - 4 } & \multicolumn{2}{c}{ CANEL } & \multicolumn{2}{c}{ SIGMA } \\
\cline { 2 - 5 } \cline { 4 - 5 } Name of device & $R_{H^{*}}$ & $u\left(R_{\left.H^{*}\right) / R_{H^{*}}}(\%)\right.$ & $R_{H^{*}}$ & $u\left(R_{\left.H^{*}\right) / R_{H^{*}}(\%)}\right.$ \\
\hline BAE SYSTEMS & 1.11 & 7 & 0.58 & 8 \\
Berthold LB 6411 & 0.85 & 7 & 0.88 & 6 \\
Harwell Leake N91 & 1.26 & 17 & - & - \\
SSI Sievert A & 1.10 & 17 & 1.28 & 11 \\
SSI Sievert B & 0.97 & 7 & 0.97 & 11 \\
Studsvik 2202D & 1.26 & 7 & 0.75 & 6 \\
\hline
\end{tabular}

The references values of $H^{*}(10)$ at CANEL and SIGMA are obtained from Refs (15) and (14), respectively. The Sievert instrument used the following approximate relation between quality factor, $Q$, and dose mean lineal energy, $y_{D}$ : $Q=$ $0.52+0.28 y_{D}$.

Table 3. Personal dose equivalent response of personal dosemeters, $R_{H \mathrm{p}}=H_{\mathrm{p}}(10)_{\text {measured }} / H_{\mathrm{p}}(10)_{\text {reference }}$ and relative standard uncertainties.

\begin{tabular}{|c|c|c|c|c|}
\hline \multirow[b]{3}{*}{ Name of device } & \multicolumn{4}{|c|}{ Facility } \\
\hline & \multicolumn{2}{|c|}{ CANEL } & \multicolumn{2}{|c|}{ SIGMA } \\
\hline & $R_{H \mathrm{p}}$ & $u\left(R_{H \mathrm{p}}\right) / R_{H \mathrm{p}}(\%)$ & $R_{H \mathrm{p}}$ & $u\left(R_{H \mathrm{p}}\right) / R_{H \mathrm{p}}(\%)$ \\
\hline Aloka PDM-313 & 5.1 & 11 & 4.3 & 6 \\
\hline BTI-PND & 1.11 & 14 & 0.69 & 15 \\
\hline DISN $1.25 \%$ & 7.3 & 15 & 20 & 12 \\
\hline DISN $1.25 \%(2 \mathrm{~mm})$ & 0.58 & 24 & 1.1 & 12 \\
\hline DISN 4\% & 2.3 & 19 & 4.2 & 13 \\
\hline DISN 4\% (1 mm) & 0.50 & 23 & 1.0 & 12 \\
\hline DOS-2002 & 1.21 & 12 & 1.19 & 7 \\
\hline HpSLAB & 1.21 & 17 & 0.99 & 14 \\
\hline PADC (NRPB) & 0.95 & 13 & 0.85 & 9 \\
\hline PADC (PSI) & 0.32 & 15 & 0.45 & 31 \\
\hline $\mathrm{PND}+\mathrm{BDT}$ & 1.32 & 13 & 1.19 & 10 \\
\hline Saphydose-n & 0.82 & 14 & 1.07 & 13 \\
\hline Siemens EPD N & 0.16 & 97 & 0.36 & 93 \\
\hline Siemens EPD N2 & 2.7 & 12 & 5.4 & 7 \\
\hline
\end{tabular}

The references values at CANEL and SIGMA are obtained from Refs (15) and (14), respectively.

water-filled phantom at angles of $0^{\circ}, 45^{\circ}$ and $75^{\circ}$ (angles are stated with respect to the normal on the front face of the phantom). Only the results for $0^{\circ}$ are presented here since the reference dose values for $45^{\circ}$ and $75^{\circ}$ are not yet available. The readings are those provided directly by the instruments based on their specific calibration procedures as established by manufacturers or developers. No attempt has been made yet to harmonise the calibration procedures of the different instruments. The uncertainties given in this paper represent first estimates of standard uncertainties although a comprehensive analysis is in progress. It is important to note that the uncertainties of the instruments' readings do not include the contributions from the energy and direction dependence of their response. For area monitors, type A uncertainties are generally negligible whereas for the personal dosemeters they are significant. The type $\mathrm{B}$ uncertainties are mostly due to uncertainties from the calibration of the instruments $(\sim 5 \%)$.

The SIGMA facility has been recently characterised by comparing MCNP-4C simulations with activation foil and spectrometer results ${ }^{(15)}$. In Table 2, the ambient dose equivalent rates measured by the area monitors are compared with a reference value $\mathrm{d} H^{*}(10) / \mathrm{d} t=(143.6 \pm 5.1) \mu \mathrm{Sv} \mathrm{h}^{-1}$. Most of the area monitors appear to underestimate the ambient dose equivalent for thermal neutrons. The personal 


\section{T. BOLOGNESE-MILSZTAJN ET AL.}

dose equivalent rates measured by personal dosemeters are compared (Table 3 ) with a reference value $\mathrm{d} H_{\mathrm{p}}(10) / \mathrm{d} t=(149.4 \pm 5.3) \mu \mathrm{Sv} \mathrm{h}^{-1(15)}$. Many personal dosemeters show agreement with the reference value within $\pm 50 \%$, but one device significantly underestimates whereas five significantly overestimate.

The CANEL facility ${ }^{(13)}$ simulates, using an accelerator generated field, neutron spectra representative of some workplaces of the nuclear industry. The neutron fluence and ambient dose equivalent $H^{*}(10)$ as a function of the energy were determined using MCNP-4C and compared with experimental values derived from spectrometry in the framework of the EUROMET intercomparison ${ }^{(14)}$. The reference value used here is the experimental one, $H^{*}(10)=122.3 \pm 6.1 \mathrm{pSv}$ per monitor count. Because of the complex irradiation conditions, dedicated computations of personal dose equivalent $H_{\mathrm{p}}(10)$ are required, which are extremely time consuming and only preliminary results are available at present ${ }^{(13)}$. Thus, the reading of the personal dosemeters can only be compared with the personal dose equivalent value derived from the EUROMET spectrometry data ${ }^{(14)}: H_{\mathrm{p}}(10)=126.5 \mathrm{pSv}$ per monitor count, i.e. assuming a broad and parallel irradiation of the phantom. The relative standard uncertainty is estimated to be $\sim 10 \%$. The responses of the area monitors presented in Table 2 show agreement with the reference dose rate within $30 \%$. Of the 14,8 personal dosemeters, show readings that deviate by less than $\pm 50 \%$ from the reference values (Table 3 ).

\section{PRELIMINARY RESULTS FROM MEASUREMENTS IN WORKPLACE FIELDS OF NUCLEAR INDUSTRY}

This paper presents preliminary results of 2 of the 10 workplaces investigated to date. The analysis of direction and energy spectrometry is not complete yet so reference values are available for $H^{*}(10)$ but not for $H_{\mathrm{p}}(10)$. The first campaign took place at the nuclear power plant in Krümmel (Germany). Measurements were performed at four workplaces. Two positions were measured at a spent fuel cask of type NTL11 ('cask midline' and 'cask side') and two other positions close to the boiling water reactor inside the reactor building: one was situated in the control rod room underneath the reactor ('reactor SAR') and the other near the top of the reactor outside the safety vessel ('reactor top'). The neutron fluence as a function of energy was measured with the IRSN Bonner-sphere spectrometer. At the cask midline, the distribution of fluence as a function of energy (Figure 1, dashed line) shows a rather hard spectrum in which $75 \%$ of the neutrons have energies between $50 \mathrm{keV}$ and $1 \mathrm{MeV}$. The ambient dose equivalent rate derived from the spectrum at this point is $\mathrm{d} H^{*}(10) /$ $\mathrm{d} t=141 \mu \mathrm{Sv} \mathrm{h}{ }^{-1}$. The energy spectrum at the position reactor SAR (Figure 1, full line) shows a thermal and a fast peak but also a non-negligible epithermal and intermediate energy neutron contribution. The ambient dose equivalent rate calculated from this spectrum is $\mathrm{d} H^{*}(10) / \mathrm{d} t=46 \mu \mathrm{Sv} \mathrm{h}{ }^{-1}$. A complete uncertainty analysis for these results is not

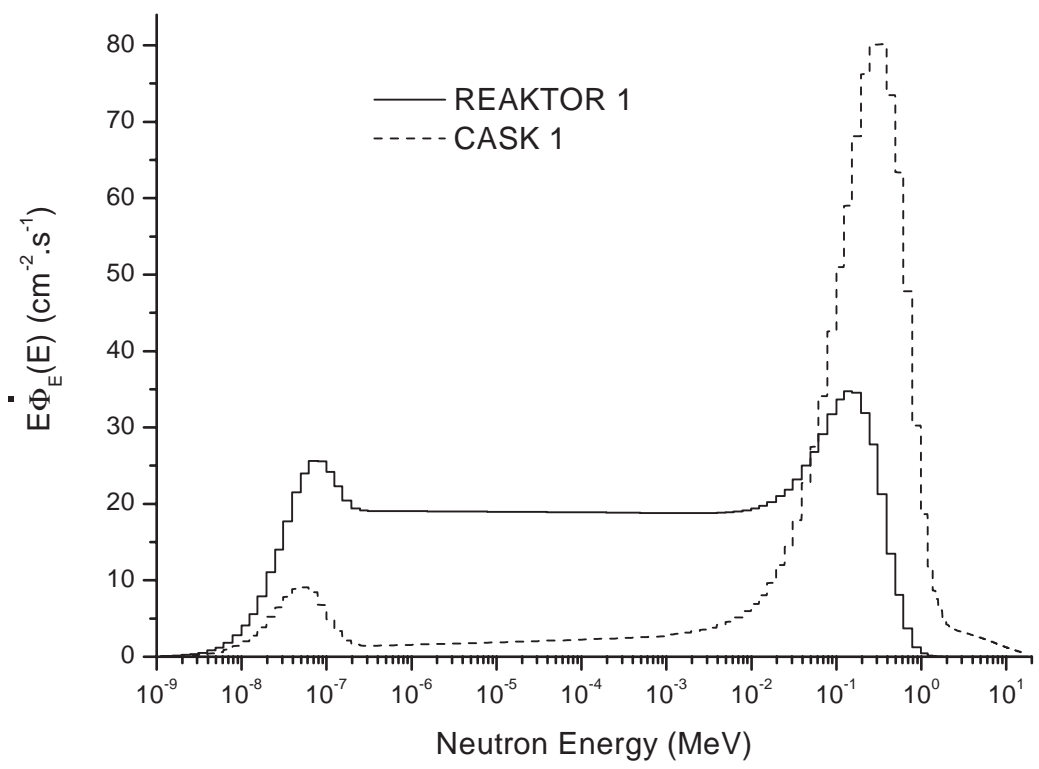

Figure 1. Relative spectral neutron fluence per logarithmic bin-width as a function of energy at Krümmel transport cask midline (CASK 1, dashed line) and reactor control rod room (SAR - reactor 1, solid line) 
INDIVIDUAL MONITORING FOR MIXED NEUTRONIPHOTON RADIATION

Table 4. Ambient dose equivalent response of area monitors: $R_{H^{*}}=H^{*}(10)_{\text {measured }} I H^{*}(10)_{\text {reference }}$ and relative standard uncertainties measured at two workplaces in Krümmel.

Name of device

Workplace

\begin{tabular}{|c|c|c|c|c|}
\hline & \multicolumn{2}{|c|}{ Cask midline } & \multicolumn{2}{|c|}{ Reactor SAR } \\
\hline & $R_{H^{*}}$ & $u\left(R_{\left.H^{*}\right) / R_{H^{*}}}(\%)\right.$ & $R_{H^{*}}$ & $u\left(R_{\left.H^{*}\right) / R_{H^{*}}}(\%)\right.$ \\
\hline BAE SYSTEMS & 0.71 & 16 & 0.92 & 16 \\
\hline Berthold LB 6411 & 0.91 & 16 & 1.30 & 16 \\
\hline Harwell Leake N91 & 0.91 & 16 & 1.30 & 16 \\
\hline SSI Sievert B & 0.84 & 22 & 1.28 & 22 \\
\hline Studsvik 2200's & 0.79 & 16 & 1.09 & 16 \\
\hline Wendi-2 & 0.93 & 16 & 1.79 & 18 \\
\hline
\end{tabular}

The reference values are derived from the Bonner-sphere measurements of the neutron energy distribution. The Sievert instrument used the following approximate relation between quality factor, $Q$, and dose mean lineal energy, $y_{D}$ : $Q=$ $0.52+0.28 y_{D}$.

yet possible. Based on previous experience with Bonner-sphere spectrometers, a conservative estimate of the relative standard uncertainty is $15 \%$.

Table 4 shows the ambient dose equivalent response of the area monitors at the two measurements positions. Except for one case, the deviations from the reference value are $<30 \%$.

The $H_{\mathrm{p}}(10)$ reference value is being evaluated using direction and energy spectrometry. This work is still in progress. However, for the cask midline position the radiation field is almost unidirectional and the reference value for $H_{\mathrm{p}}(10)$ can be approximated by $\mathrm{d} H_{\mathrm{p}}\left(10,0^{\circ}\right) / \mathrm{d} t \approx 147 \mu \mathrm{Sv} \mathrm{h}^{-1}$, derived from Bonner-sphere measurements. A large uncertainty of $30 \%$ is attributed to this value. The actual value of the $H_{\mathrm{p}}(10)$ rate is likely to be lower since the oblique components of the field will have conversion coefficients that are lower than that for $0^{\circ}$. Except for two dosemeters with negligible response, the personal dosemeter results agree within $\sim 50 \%$ with the reference values (Table 5). The results may improve once the dosemeter calibrations at the CANEL facility are fully analysed using the MCNP-computed as well as the experimental energy and direction spectra. For the measurement point under the reactor (SAR), the reference values of $H_{\mathrm{p}}(10)$ cannot be deduced from the Bonner-sphere measurements because the irradiation field was coming from the top and from room scattering on several structures surrounding the measurement point. In this case, direction spectrometry is needed to assess the behaviour of the personal dosemeters.

\section{CONCLUSIONS}

The EVIDOS programme has currently reached its mid-term. One calibration campaign and two workplace campaigns have been performed. A large
Table 5. Personal dose equivalent response of personal dosemeters, $R_{H \mathrm{p}}=H_{\mathrm{p}}(10)_{\text {measured }} / H_{\mathrm{p}}(10)_{\text {reference }}$ and relative standard uncertainties measured at Krümmel, cask midline.

\begin{tabular}{lcc}
\hline Name of device & $R_{H \mathrm{p}}$ & $u\left(R_{H \mathrm{p}}\right) / R_{H \mathrm{p}}$ \\
\hline Aloka PDM-313 & 0.96 & 31 \\
BTI-PND & 1.46 & 34 \\
HpSLAB & 1.35 & 33 \\
Local device (TLD albedo) & 1.39 & 54 \\
PADC (NRPB) & 0.47 & 36 \\
PND + BDT & 1.46 & 33 \\
PSI CR-39 & 0.31 & $>59$ \\
PSI DISN 1.25\% (2 mm) & 0.42 & 43 \\
PSI DISN 4\% (1 mm) & 0.08 & 90 \\
PTB DOS-2002 & 0.57 & 36 \\
Saphydose-n & 0.62 & 34 \\
Siemens EPD N & 0.02 & 115 \\
Siemens EPD N2 & 0.22 & 35 \\
\hline
\end{tabular}

The personal dosemeter readings are compared with $H_{\mathrm{p}}(10)$ obtained from the Bonner sphere measurement and assuming a broad, parallel incidence of neutrons.

quantity of data has already been collected and data are being analysed. Preliminary results show reasonable behaviour of several radiation protection instruments, in particular the area monitors but also several novel personal dosemeters. But they also highlight the well-known necessity to apply, for several instruments, a field-specific correction factor to derive sufficiently accurate results in workplace fields. Knowledge of the direction and energy distribution of the irradiation field is essential to understand and improve the response of the instruments used. To improve the response of personal dosemeters, a well-characterised (in energy and direction) workplace-simulated reference field is needed. 


\section{ACKNOWLEDGEMENTS}

This research is partly funded by the European Commission under the auspices of the Euratom 5th Framework Programme: Nuclear Energy, 19982002, Contract No. FIKR-CT-2001-00175. The authors wish to express their gratitude to the technical and scientific staff at Cadarache and Krümmel who helped during the campaigns, particularly to Moaad Bakali, J. L. Pochat, L. Van Ryckeghem, J. F. Guerre-Chaley, H. Muller, B. Aselineau, C. Itié, T. Lahaye, Q. Chau, P. Gerdes, G. Hallfarth, U. Schulz and U. Welte.

\section{REFERENCES}

1. Kyllönen, J., Lindborg, L. and Samuelsson, G. The response of the Sievert instrument in neutron beams up to $180 \mathrm{MeV}$. Radiat. Prot. Dosim. 94(3), 227-232 (2001).

2. Olsher, R. H., Hsu, H.-H., Beverding, A., Kleck, J. H., Casson, W. H., Vasilik, D. G. and Devine, R. T. Wendi: an improved neutron rem meter. Health Phys. 79, 170-181 (2000).

3. Bartlett, D. T., Tanner, R. J. and Jones, D. G. A new design of neutron dose equivalent survey instrument. Radiat. Prot. Dosim. 4, 267-271 (1997).

4. Luszik-Bhadra, M. Electronic personal dosemeters: the solution to problems of individual monitoring in mixed neutron/photon fields? Radiat. Prot. Dosim. 110(1-4), 747-752 (2004).

5. Gilvin, P. J., Bartlett, D. T., Shaw, P. V., Steele, J. D. and Tanner, R. J. The NRPB PADC neutron personal dosimetry service. Radiat. Prot. Dosim. 96(1-3), 191-195 (2001).

6. Lahaye, T., Chau, Q., Ménard, S., NdontchuengMoyo, M., Bolognese-Milsztajn, T. and Rannou, A. Numerical and experimental results of the operational neutron dosemeter 'Saphydose- $N$ '. Radiat. Prot. Dosim. 110(1-4), 201-206 (2004).

7. Fiechtner, A., Boschung, M. and Wernli, C. Present status of the personal neutron dosemeter based on direct ion storage. Radiat. Prot. Dosim. 110(1-4), 213-217 (2004).

8. Luszik-Bhadra, M., Wendt, W. and Weierganz, M. The electronic neutron/photon dosemeter PTB DOS2002. Radiat. Prot. Dosim. 110(1-4), 291-295 (2004).

9. d'Errico, F., Apfel, R. E., Curzio, G. and Nath, R. Electronic personal neutron dosimetry with superheated drop detectors. Radiat. Prot. Dosim. 96(1-3), 261-264 (2001).

10. Lacoste, V., Gressier, V., Pochat, J. L., Fernández, F., Bakali, M. and Bouassoule, T. Characterization of Bonner sphere systems at mono-energetic and thermal neutron fields. Radiat. Prot. Dosim. 110(1-4), 529-532 (2004).

11. d'Errico, F., Giusti, V., Reginatto, M. and Wiegel, B. A telescope design directional neutron spectrometer. Radiat. Prot. Dosim. 110(1-4), 533-537 (2004).

12. Luszik-Bhadra, M., Reginatto, M. and Lacoste, V. Measurement of energy and directional distribution of neutron and photon fluences at workplace fields. Radiat. Prot. Dosim. 110(1-4), 237-241 (2004).

13. Lacoste, V. and Gressier, V. MCNP4C simulation of the IRSN CANEL/T400 realistic mixed neutron-photon radiation field. Radiat. Prot. Dosim. 110(1-4), 123-127 (2004).

14. Gressier, V. and 13 others. Characterization of the IRSN CANEL/T400 facility producing realistic neutron fields for calibration and test purposes. Radiat. Prot. Dosim. 110(1-4), 522-527 (2004).

15. Lacoste, V., Gressier, V., Muller, H. and Lebreton, L. Characterization of the IRSN graphite moderated americium-beryllium neutron field. Radiat. Prot. Dosim. 110(1-4), 135-139 (2004).

16. Reginatto, M., Luszik-Bhadra, M. and d'Errico, F. An unfolding method for directional spectrometers. Radiat. Prot. Dosim. 110(1-4), 539-543 (2004).

17. Vanhavere, F. and d'Errico, F. Standardisation of superheated drop and bubble detectors. Radiat. Prot. Dosim. 101(1-4), 283-287 (2002).

18. d'Errico, F., Luszik-Bhadra, M. and Lahaye, T. State of the art of electronic personal dosimeters for neutrons. Nucl. Instrum. Meth. Phys. Res. A 505(1-2), 411-414 (2003). 